\title{
Is sex a risk factor for death in patients with bilateral internal thoracic artery grafts?
}

Juan Mariano Vrancic, MD, ${ }^{\mathrm{a}}$ Daniel Oscar Navia, MD, ${ }^{\mathrm{a}}$ Juan Carlos Espinoza, MD,

Fernando Piccinini, MD, ${ }^{\mathrm{a}}$ Mariano Camporrotondo, MD, ${ }^{\mathrm{a}}$ Mariano Benzadon, MD, ${ }^{\mathrm{b}}$ and Alberto Dorsa, $\mathrm{MD}^{\mathrm{c}}$

\section{ABSTRACT}

Background: Mortality after coronary artery bypass grafting (CABG) has been reported to be higher in women. The aim of this study was to evaluate whether bilateral internal thoracic artery (BITA) grafting in women has a long-term survival benefit over single internal thoracic artery grafting, possibly equivalent to the male population.

Methods: A retrospective review was undertaken of our prospectively collected database. We included 4406 consecutive patients who underwent isolated CABG, who received their operation between January 2000 and April 2017. From the entire series, 2979 patients $(67.6 \%)$ received exclusively BITA grafts; $299(10.1 \%)$ were female. The primary end point was follow-up mortality, independently from cause. In-hospital mortality and during follow-up were analyzed. Substratification according to age was performed to answer whether it has an effect. Multivariable Cox proportional hazard analyses was performed to investigate the significant predictors of late mortality.

Results: The median follow-up was $5.1 \pm 3.9$ years. Female BITA patients were older $(P<.001)$, had nonelective surgery $(P<.001)$, more on-pump CABG $(P=.015)$, fewer number of grafts $(P<.001)$ versus male BITA patients. BITA grafting in women had a long-term survival equivalent to that of men $(P=.784)$.

In a Cox proportional hazard model, female sex was not an independent risk factor for late death $(\mathrm{B},-0.303$; hazard ratio, $0.739 ; 95 \%$ confidence interval, $0.470-1.16 ; P=.189)$. The stratification analysis showed that the beneficial effect of BITA remained similar among sexes and was not modified by age even after adjusting for confounders. In a risk-adjusted sample, patients older than 65 years with BITA grafting showed superior long-term survival than those with single internal thoracic artery grafting $(P=.019)$

Conclusions: Although there are some differences between sexes, BITA grafting in women was associated with similar 10-year survival compared with men, and female sex was not an independent risk factor for late death. Among women, the BITA group had better survival, especially those older than 65 years. (J Thorac Cardiovasc Surg 2019;158:1345-53)

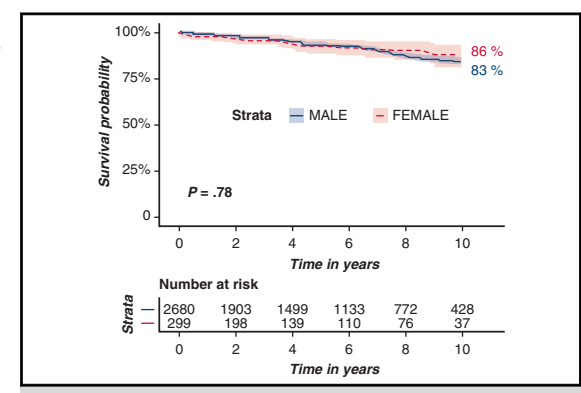

There were no differences in long-term survival between male and female BITA groups.

\section{Central Message}

BITA grafting in women was associated with similar survival within 10 years compared with men. Among women, the BITA group had better survival than the SITA group, especially in participants older than 65 years.

\section{Perspective}

Mortality rate after CABG has been reported to be higher in women and might be attributed to the limited use of BITA grafting in women. Regular use of BITA grafting has shown a low incidence of postoperative complications, including mediastinitis, and implies an excellent 10-year survival, similar to that reported for the male population. These results might support the extended indication for BITA in women.

See Commentaries on pages 1354 and 1356.
Coronary disease was, for many years, considered predominantly a male disease; nevertheless, it represents a leading cause for mortality for women worldwide, even greater than that in the male population in developed countries like the

\footnotetext{
From the Departments of ${ }^{\text {a }}$ Cardiac Surgery, and ${ }^{\mathrm{c}}$ Cardiovascular Anesthesia, and ${ }^{\mathrm{b}}$ Cardiovascular Recovery Unit, Instituto Cardiovascular De Buenos Aires, Buenos Aires, Argentina.

Read at the 98th Annual Meeting of The American Association for Thoracic Surgery, San Diego, California, April 28-May 1, 2018.

Received for publication April 29, 2018; revisions received Dec 23, 2018; accepted for publication Jan 3, 2019; available ahead of print March 20, 2019.
}

United States. Coronary artery disease incidence might have a delayed presentation and diagnosis in women by 10 years, up to 20 years for serious clinical events like myocardial infarction or sudden death. ${ }^{1-3}$

\footnotetext{
Address for reprints: Juan Mariano Vrancic, MD, Instituto Cardiovascular de Bueno Aires, Libertador 6302, 1428 Buenos Aires, Argentina (E-mail: jmvrancic@icba. com.ar). $0022-5223 / \$ 36.00$

Copyright $(\underset{2019}{ }$ by The American Association for Thoracic Surgery https://doi.org/10.1016/j.jtcvs.2019.01.025
} 

Abbreviations and Acronyms
BITA = bilateral internal thoracic artery
$\mathrm{CABG}=$ coronary artery bypass grafting
$\mathrm{CI}=$ confidence interval
$\mathrm{HR}=$ hazard ratio
LITA $=$ left internal thoracic artery
RA = radial artery
RITA = right internal thoracic artery
SITA $=$ single internal thoracic artery
STS = Society of Thoracic Surgeons

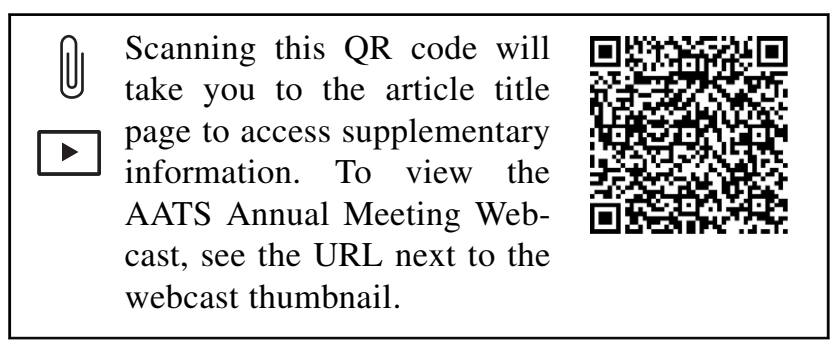

Coronary artery disease in women is associated with worse prognosis over that in men, mainly a greater incidence of heart failure within 5 years after myocardial infarction, or post coronary artery bypass grafting (CABG) mortality. Even further, female sex has been established as a risk factor for frequently used preoperative risk scores, such as the Society of Thoracic Surgeons (STS) or the European System for Cardiac Operative Risk Evaluation. ${ }^{4,5}$ Compared with the male population undergoing CABG surgery, younger women represent the higher-risk group, with decreasing significance with advancing age. ${ }^{6}$

Regarding the CABG procedure itself, there is a significant sex differentiation, such as a small percentage of women who receive complete arterial revascularization, as reported in the STS database $(2.3 \%$ of women who underwent CABG from 2002 to 2005 received bilateral internal thoracic artery [BITA] grafting vs $4.7 \%$ of men). ${ }^{7,8}$

Therefore, it seems that female sex, considered as a risk factor, precludes women from receiving probably the best revascularization approach, BITA grafting. Whether the systematic use of BITA grafting among women provides any beneficial effect regarding long-term survival remains uncertain..$^{9,10}$

As people live longer and the population ages, more elderly patients are being referred for CABG. In most studies, BITA was used preferentially in a selected group of young or low-risk patients and the risk and benefit of BITA grafting in elderly patients has not been well investigated. ${ }^{11,12}$

The primary aim of the current study was to determine if BITA grafting as a standard approach for coronary revascularization in women has a long-term effect as shown for the male population, and secondarily to compare survival in women who receive BITA versus single internal thoracic artery (SITA), with a 65-year-old threshold.

\section{METHODS}

This was a single-center study, on the basis of clinical data obtained from our computerized database, in which prospective information on cardiac surgery procedures is collected. We included a total of 4406 consecutive patients with isolated CABG surgery from January 2000 to April 2017.

The entire series was divided into 2 groups: (1) BITA in a T configuration (BITA group), 2979 patients, 299 (10\%) women; and (2) SITA with other conduits group (SITA group), 1427 patients, 207 (15\%) women. Within the SITA group, 627 patients (43.9\%) received an additional radial artery (RA), 540 patients (37.8\%) RA and saphenous vein graft, and 260 patients $(18.2 \%)$ only an additional vein graft.

\section{End Points}

The primary end point of the study was to analyze whether survival within 10 years between women and men with BITA are equivalent. Thirty-day morbidity and mortality after CABG between the groups were analyzed. Follow-up mortality was 548 patients $(12.4 \%)$, reported as cardiac $(117 / 548 ; 21.3 \%)$, noncardiac death (236/548; $43.2 \%)$, and undefined causes $(195 / 548 ; 35.5 \%)$.

\section{Surgical Technique}

The indication for myocardial revascularization was on the basis of standard clinical and angiographic criteria. All operations were through median sternotomy. Harvesting of thoracic arteries in the BITA group was performed using exclusively a skeletonized technique, with low levels (25 dissect) for standard electrocautery and conventional clips for collateral branch occlusion. Most patients in both groups, underwent off-pump CABG, our preferred revascularization technique since 2002. For all patients we used full-dose heparin (Video 1).

The surgical technique used for the BITA group has been previously reported $^{13}$ and consists of using both internal thoracic arteries as exclusive conduits for revascularization. The technical configuration most commonly used was in situ left internal thoracic artery (LITA) to the left anterior descending artery, and right internal thoracic artery (RITA) as a free-graft, end-to-side in T from the LITA and sequentially grafted to the circumflex and distal right coronary artery. For significant stenosis on a diagonal branch, we might perform a sequential LITA to diagonal left anterior descending artery grafting or a short $\mathrm{T}$ graft from the RITA using a distal segment of the remaining LITA or RITA, according to surgeon preference.

More than 1 circumflex branch can be reached through diamond sequential grafting with RITA and finally it can be anastomosed to the distal right coronary artery. Marginal branches with less than $70 \%$ stenosis, were not grafted. We do not use in situ RITA.

Regarding competitive flow, we studied a subgroup of patient with postoperative angiography and when native vessel stenosis was $>70 \%$, there was no competitive flow. Similar results have been reported. ${ }^{14,15}$

In the SITA group, LITA was grafted almost exclusively to the left anterior descending artery, and the saphenous vein and/or the RA were grafted to remaining vessels. The RA was used mainly from the LITA as a T graft to the circumflex artery, and the saphenous vein was anastomosed from a partially clamped aorta, to the right coronary artery, in off-pump patients. The quality of the anastomosis was assessed using transit time flow measurement probes (VeriQ System; Medistim, Oslo, Norway).

A strict protocol of glycemic control was started intraoperatively and continued in the intensive care unit with a correction threshold of 
$180 \mathrm{mg} / \mathrm{dL}$. Insulin was used as an intravenous bolus or continuous infusion according to a previously established algorithm. ${ }^{16}$

We used cefazolin $2 \mathrm{~g}$ preoperatively within 60 minutes before the skin incision and continued for no longer than 48 hours. Redosing is indicated for procedures $>4$ hours. We do not routinely use vancomycin paste or bone wax. ${ }^{17}$

\section{Statistical Analyses}

Preoperative characteristics of patients in these study groups were summarized as mean \pm standard deviation, median and interquartile range, or prevalence (in percentage), as appropriate. Student $t$ test for independent samples or Mann-Whitney $U$ test for continuous variables, and $\chi^{2}$ tests for categorical variables were applied to examine differences between groups.

Follow-up data were collected for 180 female BITA patients $(91 \%$; mean, 4.3 years; range, 2 months to 12.8 years) and 133 female SITA patients $(93 \%$; mean, 6.8 years; range, 2 months to 16.3 years; $P<.001)$. The cumulative follow-up for BITA patients was 774 patient-years and for SITA were 904.4 patient-years.

A propensity score of having BITA versus SITA among women was calculated for each patient using a logistic regression model that included all of the preoperative variables listed in Table 1. Patients were matched 1:1 according to the propensity score using the greedy matching technique without replacement. A nearest neighbor matching algorithm was used with a caliper distance of 0.01 . Outcomes of interest between the matched groups were compared using the paired $t$ test for continuous variables and the McNemar test for categorical variables. Substratification according to age (younger and older than 65 years old) was performed to answer whether age was related to survival.

Event-free survival curves were estimated using the Kaplan-Meier method. The log rank test was used to assess the differences in survival between the 2 groups.

A multivariable stepwise logistic regression was used to adjust for baseline differences between groups and to obtain independent predictors of outcome within 30 days of surgery; and univariable and multivariable Cox proportional hazard analyses were performed to investigate the significant predictors of late mortality. The preoperative variables used for univariate analysis are listed in Table 2.

Variables with $P<.2$ in univariate analyses were included in the multivariate model. A statistical level of significance was established as $P<.05$.

All analyses were done using SPSS Statistics (version 21; IBM Corp, Armonk, NY) and in R 2.14.0 (The R Project for Statistical Computing, Vienna, Austria) using the survminer package. The study protocol was approved by the institutional ethical committee, and written informed consent was obtained from all of the patients regarding the surgical method and the postoperative evaluations.

TABLE 1. Patient characteristics and intraoperative data (all women older than 65 years) BITA versus SITA comparison

\begin{tabular}{|c|c|c|c|c|c|c|}
\hline \multirow[b]{2}{*}{ Preoperative variable } & \multicolumn{3}{|c|}{ Nonmatched groups } & \multicolumn{3}{|c|}{ Propensity matched groups } \\
\hline & $\overline{\text { SITA }(n=147)}$ & BITA $(n=186)$ & SMD & $\overline{\text { SITA }(n=131)}$ & BITA $(n=131)$ & SMD \\
\hline Mean age $( \pm S D), y$ & $73.9 \pm 5.1$ & $73.5 \pm 5.2$ & 0.083 & $70.2 \pm 8.7$ & $69.0 \pm 8.7$ & 0.142 \\
\hline Mean weight $( \pm \mathrm{SD}), \mathrm{kg}$ & $62.3 \pm 28.9$ & $68.9 \pm 22.8$ & 0.106 & $65.1 \pm 26.9$ & $65.1 \pm 20.1$ & 0.229 \\
\hline Mean height $( \pm \mathrm{SD}), \mathrm{cm}$ & $156.1 \pm 32.2$ & $159.0 \pm 34.3$ & 0.077 & $155.4 \pm 44.7$ & $156.3 \pm 42.6$ & 0.005 \\
\hline Hypertension, $\mathrm{n}(\%)$ & $114(77.6)$ & $164(88.2)$ & 0.285 & $105(80.2)$ & $106(80.9)$ & 0.019 \\
\hline Smoking history, n (\%) & $32(21.8)$ & $63(33.9)$ & 0.273 & $38(29)$ & $52(39.7)$ & 0.226 \\
\hline Diabetes mellitus, n (\%) & $45(30.6)$ & $56(30.1)$ & 0.011 & $44(33.6)$ & $42(32.3)$ & 0.049 \\
\hline Family history of coronary disease, $\mathrm{n}(\%)$ & $28(19)$ & $50(26.9)$ & 0.187 & $39(29.8)$ & $42(32.1)$ & 0.05 \\
\hline Previous MI, n (\%) & $51(34.4)$ & $73(39.2)$ & 0.08 & $43(32.8)$ & $47(35.9)$ & 0.064 \\
\hline Previous PCI, n (\%) & $27(18.4)$ & $24(12.9)$ & 0.151 & $23(17.6)$ & $23(17.6)$ & $<0.001$ \\
\hline Redo surgery, n (\%) & $5(3.4)$ & $0(0)$ & 0.265 & $0(0)$ & $0(0)$ & $<0.001$ \\
\hline Peripheral artery disease, $\mathrm{n}(\%)$ & $4(2.7)$ & $13(7)$ & 0.2 & $5(3.8)$ & $7(5.3)$ & 0.073 \\
\hline COPD, n $(\%)$ & $1(0.7)$ & $8(4.3)$ & 0.234 & $3(2.3)$ & $6(4.6)$ & 0.126 \\
\hline Cerebrovascular disease, $\mathrm{n}(\%)$ & $6(4.1)$ & $4(2.2)$ & 0.111 & $5(3.8)$ & $6(4.6)$ & 0.038 \\
\hline Renal dysfunction, n (\%) & $5(3.4)$ & $12(6.5)$ & 0.141 & $5(3.8)$ & $3(2.3)$ & 0.089 \\
\hline Anemia, N (\%) & $20(13.6)$ & $25(13.4)$ & 0.005 & $21(16)$ & $15(11.5)$ & 0.133 \\
\hline Impaired ejection fraction $(<0.40), \mathrm{n}(\%)$ & $23(15.6)$ & $19(10.2)$ & 0.162 & $22(16.8)$ & $17(13)$ & 0.107 \\
\hline Left main CAD, n (\%) & $29(19.5)$ & $45(24.1)$ & 0.183 & $29(22.1)$ & $29(22.3)$ & 0.184 \\
\hline Mean vessel disease $( \pm \mathrm{SD})$ & $2.7 \pm 0.7$ & $2.9 \pm 0.9$ & 0.361 & $2.8 \pm 0.9$ & $2.7 \pm 0.9$ & 0.360 \\
\hline Nonelective surgery, n (\%) & $80(54.4)$ & $82(44.1)$ & 0.208 & $77(58.8)$ & $65(49.6)$ & 0.185 \\
\hline \multicolumn{7}{|l|}{ Intraoperative data } \\
\hline On-pump, n (\%) & $47(32)$ & $6(3.2)$ & 0.815 & $6(4.6)$ & $7(5.3)$ & 0.035 \\
\hline Mean number of grafts $( \pm \mathrm{SD})$ & $2.7 \pm 0.6$ & $2.9 \pm 0.6$ & 0.363 & $2.9 \pm 0.7$ & $3.0 \pm 0.7$ & 0.249 \\
\hline Mean bypass time ( \pm SD), minutes & $85.7 \pm 30.5$ & $64.0 \pm 24$ & 1.352 & $83.8 \pm 11.1$ & $69.9 \pm 22$ & 1.255 \\
\hline
\end{tabular}

SITA, Single internal thoracic artery; $B I T A$, bilateral internal thoracic artery; $S M D$, standardized mean difference; $S D$, standard deviation; $M I$, myocardial infarction; $P C I$, percutaneous coronary intervention; $C O P D$, chronic obstructive pulmonary disease; $C A D$, coronary artery disease. 
TABLE 2. Patient characteristics and intraoperative data (all BITA) sex comparison

\begin{tabular}{|c|c|c|c|}
\hline Preoperative variable & Male $(n=2680)$ & Female $(n=299)$ & SMD \\
\hline Mean age $( \pm S D), y$ & $63.8 \pm 9.9$ & $67.8 \pm 9.1$ & 0.422 \\
\hline Mean weight $( \pm \mathrm{SD}), \mathrm{kg}$ & $83.7 \pm 29$ & $69.2 \pm 25.1$ & 0.448 \\
\hline Mean height $( \pm \mathrm{SD})$, cm & $171.7 \pm 27.4$ & $159.5 \pm 30.3$ & 2.119 \\
\hline Hypertension, n (\%) & $2082(77.7)$ & $247(82.6)$ & 0.123 \\
\hline Smoking history, n (\%) & $1814(67.7)$ & $136(45.5)$ & 0.445 \\
\hline Diabetes mellitus, n (\%) & $737(27.5)$ & $90(30.1)$ & 0.057 \\
\hline Family history of coronary disease, $\mathrm{n}(\%)$ & $673(25.1)$ & $82(27.4)$ & 0.052 \\
\hline Previous MI, n (\%) & $1120(41.8)$ & $107(35.8)$ & 0.124 \\
\hline Previous PCI, n (\%) & $598(22.3)$ & $45(15.1)$ & 0.187 \\
\hline Redo surgery, n (\%) & $16(0.6)$ & $0(0)$ & 0.11 \\
\hline Peripheral artery disease, $\mathrm{n}(\%)$ & $78(2.9)$ & $15(5)$ & 0.11 \\
\hline COPD, n (\%) & $153(5.7)$ & $11(3.7)$ & 0.098 \\
\hline Cerebrovascular disease, $\mathrm{n}(\%)$ & $102(3.8)$ & $9(3)$ & 0.046 \\
\hline Renal dysfunction, n (\%) & $137(5.1)$ & $15(5)$ & 0.006 \\
\hline Anemia, n (\%) & $137(5.1)$ & $36(12)$ & 0.248 \\
\hline Impaired ejection fraction $(<0.40), \mathrm{n}(\%)$ & $386(14.4)$ & $32(10.7)$ & 0.111 \\
\hline Left main CAD, n (\%) & $630(23.5)$ & $57(19.1)$ & 0.179 \\
\hline Mean vessel disease $( \pm \mathrm{SD})$ & $2.7 \pm 0.8$ & $2.6 \pm 0.9$ & 0.361 \\
\hline Nonelective surgery, n (\%) & $906(33.8)$ & $129(43.1)$ & 0.193 \\
\hline \multicolumn{4}{|l|}{ Intraoperative data } \\
\hline On-pump, n (\%) & $24(0.9)$ & $7(2.3)$ & 0.118 \\
\hline Mean number of grafts $( \pm \mathrm{SD})$ & $3.2 \pm 0.7$ & $2.9 \pm 0.7$ & 0.355 \\
\hline Mean bypass time $( \pm \mathrm{SD})$, minutes & $92.9 \pm 35.1$ & $63.9 \pm 23.9$ & 1.235 \\
\hline
\end{tabular}

$S M D$, Standardized mean difference; $S D$, standard deviation; $M I$, myocardial infarction; $P C I$, percutaneous coronary intervention; $C O P D$, chronic obstructive pulmonary disease; $C A D$, coronary artery disease.

\section{RESULTS}

\section{Patient Characteristics}

The basal characteristics for the entire population were as follows: mean age $65 \pm 10$ years, $12.4 \%$ female sex, and $27.9 \%$ of the patients were diabetic. The off-pump technique was the preferred one in most patients $(87 \%)$, nonelective surgery was done in $36.4 \%$ of cases, and the BITA strategy was used in $67.6 \%$ of patients (Table E1).

\section{Male/Female BITA Population}

There were important differences between BITA male $(n=2680)$ and female $(n=299)$ groups. Women were older, had had smaller body surface area, had had more peripheral vascular disease, more anemia, and had more nonelective surgery (Table 2).

Unadjusted early outcomes for BITA patients are presented in Table 3. BITA women had higher postoperative mortality $(2.3 \%$ vs $1 \%)$, postoperative stroke $(1.3 \%$ vs $0.3 \%)$, and mediastinitis ( $3.3 \%$ vs $1.5 \%)$. After adjusting for confounders female sex was not an independent predictor for death within 30 days of surgery in the multivariable regression model (odds ratio, 1.754; 95\% confidence interval $[\mathrm{CI}], 0.743-4.144 ; P=.2$ ). Nevertheless, it should be noticed that the number of events among women was small in proportion (Table 3).

Survival within 10 years of BITA was $86 \%$ for women and $83 \%$ for men (Figure 1). In the Cox proportional hazard model, female sex was not an independent risk factor for late death $(\mathrm{B},-0.303$; hazard ratio [HR], 0.739; 95\% CI, $0.470-1.16 ; P=.189)$, age (B, 0.050; HR, 1.051; $95 \%$ CI, 1.04-1.06; $P=.000$ ); chronic renal failure $(\mathrm{B}, .672$; HR, $1.957 ; 95 \%$ CI $1.272-3.010 ; P=.002$ ); diabetes mellitus (B, .422; HR, 1.525; 95\% CI, 1.172-1.983; $P=.002$ ); non-sinus rhythm (B, 0.458; HR, 1.582; 95\% CI, 1.1-2.275; $P=.013$ ); left ventricular dysfunction (B, 0.530; HR, 1.699; 95\% CI, 1.257-2.296; $P=.001$ ), and peripheral vascular disease $(\mathrm{B}, 1.231$; HR, 3.426; 95\% CI, 2.244$5.229 ; P=.000)$ were independent predictors for late death. Data on the need for reintervention between groups was not an objective of this study and will be the reason for a future report. 
TABLE 3. Early outcomes (all BITA) sex comparison

\begin{tabular}{lcccc}
\hline \multicolumn{1}{c}{ Variable } & $\begin{array}{c}\text { Male } \\
(\mathbf{n = 2 6 8 0})\end{array}$ & $\begin{array}{c}\text { Female } \\
(\mathbf{n = 2 9 9 )}\end{array}$ & $\begin{array}{c}\text { Total } \\
(\mathbf{N = 2 9 7 9 )}\end{array}$ & $\begin{array}{c}\boldsymbol{P} \\
\text { value }\end{array}$ \\
\hline Death & $27(1.0)$ & $7(2.3)$ & $36(1.2)$ & .048 \\
Stroke & $8(0.3)$ & $4(1.3)$ & $12(0.4)$ & .013 \\
Mediastinitis & $40(1.5)$ & $10(3.3)$ & $51(1.7)$ & .022 \\
Atrial fibrillation & $338(12.6)$ & $31(10.4)$ & $369(12.4)$ & .264 \\
Myocardial infarction & $27(1.0)$ & $7(2.3)$ & $57(1.9)$ & .750 \\
Dialysis & $19(0.7)$ & $2(0.7)$ & $21(0.7)$ & .882 \\
Reoperation for bleeding & $48(1.8)$ & $6(2)$ & $54(1.8)$ & .754 \\
\hline
\end{tabular}

Data are presented as $\mathrm{n}(\%)$ except where otherwise noted.

\section{Female BITA Versus SITA}

When we divided the female population older than 65 years old into the BITA or SITA strategy groups there were marked differences in basal characteristics, which were eliminated in the propensity score analysis (131 patients per group), as shown in Table 1.

Unadjusted, the SITA population older than 65 years had a greater incidence of postoperative mortality $(5.7 \%$ vs $3.2 \%)$. These differences disappeared with the propensity adjusted data (Table 4). There were no differences in survival between SITA patients compared with LITA/ saphenous vein versus LITA/RA, either in the total population or in women.

The unadjusted long-term survival was greater for female BITA patients, regardless of age $(86 \%$ vs $76 \% ; P=.04$; Figure 2, A). These differences were even greater when we compared the propensity groups $(87 \%$ vs $70 \%$; $P=.01$; Figure 2, $B$ ).

Between SITA patients, there were no differences in survival in the LITA/saphenous vein versus the LITA/RA
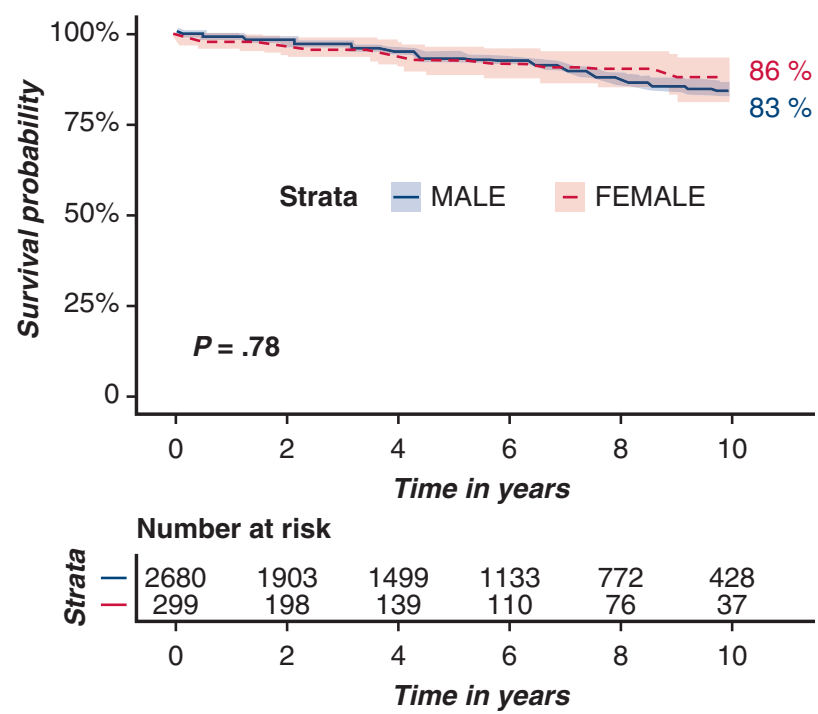

FIGURE 1. Kaplan-Meier survival estimates with number of subjects at risk and 95\% Hall-Wellner bands. groups, either in total population or in women. Female BITA patients older than 65 years showed a significant benefit in long-term survival in the risk-adjusted data $(87 \%$ vs $73 \% ; P=.019$; Figure 3$)$. Finally, for women younger than 65 years, there were no differences in survival between BITA and SITA patients either in total or in propensity matched data.

\section{DISCUSSION}

It has been reported that women who undergo CABG have worse short- and long-term outcomes in terms of morbidity and mortality compared with men. These poor results have been especially attributed to preoperative factors such as older age, greater number of comorbidities, smaller body surface area, more nonelective surgery, and fewer number of bypasses performed, perhaps because of small vessels. This last item might be related to urgency/emergency condition at the time of surgery and also to comorbidities.

STS score and European System for Cardiac Operative Risk Evaluation II includes sex in the risk model, but they do not consider coronary vessels size or the less-used LITA-BITA. All of these conditions are commonly present in women and might influence long-term results more than female sex per se. ${ }^{4,5}$ Because arterial conduit permeability is greater than in the saphenous vein, it has been proposed that less use of LITA in women can have a negative effect on outcomes compared with men. ${ }^{18-20}$

Saxena and colleagues ${ }^{21}$ showed in their study on the basis of an Australian database, that women have worse postoperative results than men. They concluded that sex differences might be not only on the basis of preoperative factors but also surgical technique - that is, LITA and other arterial conduit use-which were significantly less used in women.

Other authors like Aldea and colleagues have emphasized the importance of internal thoracic artery use in CABG mortality reduction in women. ${ }^{22}$ However, very few have studied the importance of using BITA to further improve this condition. ${ }^{9,10}$

We found differences in death, stroke, and a greater incidence of superficial and deep sternal wound infection in the female-BITA versus male-BITA groups; the same was mentioned by Kurlansky and colleagues. ${ }^{10}$ Among women, there were no statistical differences in mediastinitis in the SITA versus BITA groups. The most recent STS Adult Cardiac Surgery Database ${ }^{23}$ showed a lower incidence rate of deep sternal wound infection than we did in this study, but it is important to note that BITA grafting was used in only $5 \%$ of CABG patients in this database (STS 2018) and we do not know the incidence of mediastinitis in this subgroup of patients.

The Arterial Revascularisation Trial (ART) study,${ }^{24}$ the first randomized study to compare SITA versus BITA 
TABLE 4. Early outcomes (all women older than 65 years); BITA versus SITA comparison

\begin{tabular}{|c|c|c|c|c|c|c|c|c|}
\hline \multirow[b]{2}{*}{ Variable } & \multicolumn{4}{|c|}{ Nonmatched groups } & \multicolumn{4}{|c|}{ Propensity matched groups } \\
\hline & $\begin{array}{c}\text { SITA } \\
(n=147)\end{array}$ & $\begin{array}{c}\text { BITA } \\
(\mathrm{n}=186)\end{array}$ & $\begin{array}{c}\text { Total } \\
(\mathrm{n}=\mathbf{3 3 3})\end{array}$ & $P$ value & $\begin{array}{c}\text { SITA } \\
(n=131)\end{array}$ & $\begin{array}{c}\text { BITA } \\
(n=131)\end{array}$ & $\begin{array}{c}\text { Total } \\
(\mathrm{n}=\mathbf{2 6 2})\end{array}$ & $P$ value \\
\hline Death, n (\%) & $8(5.7)$ & $6(3.2)$ & $15(4.45)$ & .016 & $7(5.5)$ & $4(3.1)$ & $11(4.3)$ & .732 \\
\hline Stroke, n (\%) & $2(1.4)$ & $2(1.1)$ & $4(1.2)$ & .812 & $1(.8)$ & $2(1.5)$ & $3(1.1)$ & .165 \\
\hline Mediastinitis, n (\%) & $1(0.7)$ & $7(3.8)$ & $8(2.4)$ & .068 & $1(.8)$ & $5(3.8)$ & $6(2.3)$ & .990 \\
\hline Atrial Fibrillation, n (\%) & $26(17.7)$ & $28(15.1)$ & $54(16.2)$ & .517 & $22(16.8)$ & $19(14.5)$ & $41(15.6)$ & .116 \\
\hline Myocardial Infarction, n (\%) & $4(2.7)$ & (2.1) & $8(2.4)$ & .736 & $3(2.3)$ & $5(3.8)$ & $8(3.1)$ & .374 \\
\hline Dialysis, $\mathrm{n}(\%)$ & $5(3.4)$ & $2(1.1)$ & $7(2.1)$ & .142 & $5(3.8)$ & $0(0)$ & $5(1.9)$ & .024 \\
\hline Reoperation for bleeding, $\mathrm{n}(\%)$ & $5(3.4)$ & $4(2.2)$ & $9(2.7)$ & .485 & $3(2.3)$ & $1(.8)$ & $4(1.5)$ & .413 \\
\hline
\end{tabular}

SITA, Single internal thoracic artery; BITA, bilateral internal thoracic artery.

patients, reported that BITA patients have a greater incidence of deep sternal wound infection than SITA patients. It is well established that the skeletonized harvesting technique in BITA reduces the incidence of mediastinitis, ${ }^{25,26}$ but it was not a condition for BITA use in this trial. In an ART substudy, presented by Benedetto and colleagues ${ }^{27}$ it was suggested that the risk of sternal wound infection with skeletonized BITA is similar to that in harvesting the SITA graft using the standard pedicle technique. We have previously published that neither the use of BITA nor female sex were independent predictors of deep sternal wound infection in multivariate analysis. ${ }^{28}$ In a recent study by Rieß and colleagues ${ }^{29}$ using BITA with the skeletonized technique in all-comer patients, they reported a low incidence of mediastinitis and similar long-term survival in a comparison of women with men, as we do in this report.
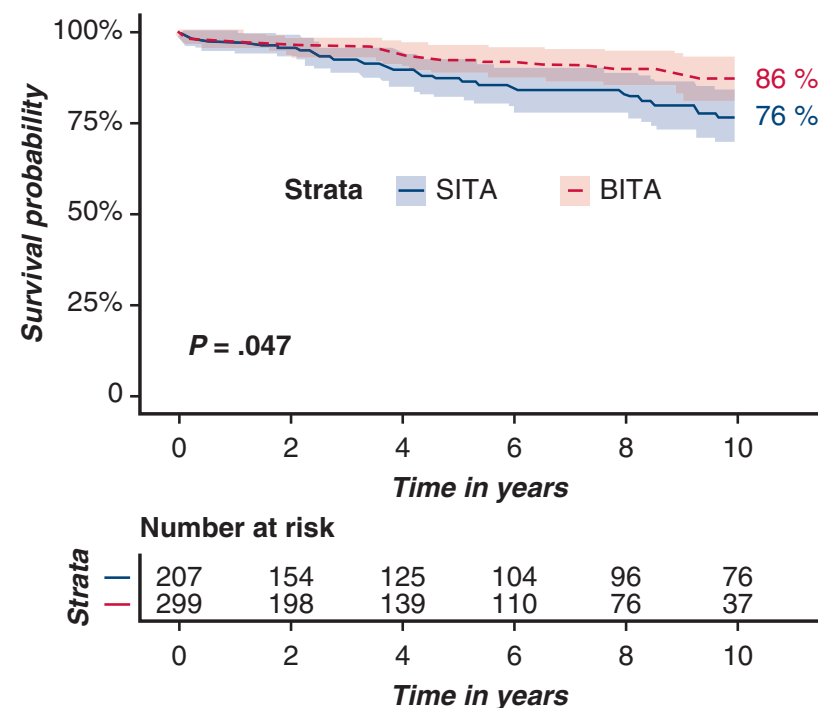

A

Time in years
Long-term mortality is not different between women and men. So, it could be that BITA use might offer women a protective effect in long-term survival and put them in the same conditions as men in these aspects of CABG. The same was suggested by some other authors. ${ }^{30,31}$

The use of BITA grafts in elderly patients is controversial. He and coworkers ${ }^{32}$ reported an operative mortality of $24 \%$ in elderly patients (older than 70 years) who underwent BITA grafting. However, in a study of Galbut and associates, ${ }^{12}$ patients with BITA had a lower hospital mortality rate $(3.1 \%)$ than patients with a SITA $(6.4 \%)$, and the late survival (mean, 43 months) was better as well $(69.7 \%$ vs $60.7 \%)$. They recommended the routine use of bilateral skeletonized internal thoracic artery grafting for most patients 70 years and older.

Pettinari and colleagues ${ }^{33}$ and Kinoshita and colleagues $^{34}$ reported better survival in old BITA patients

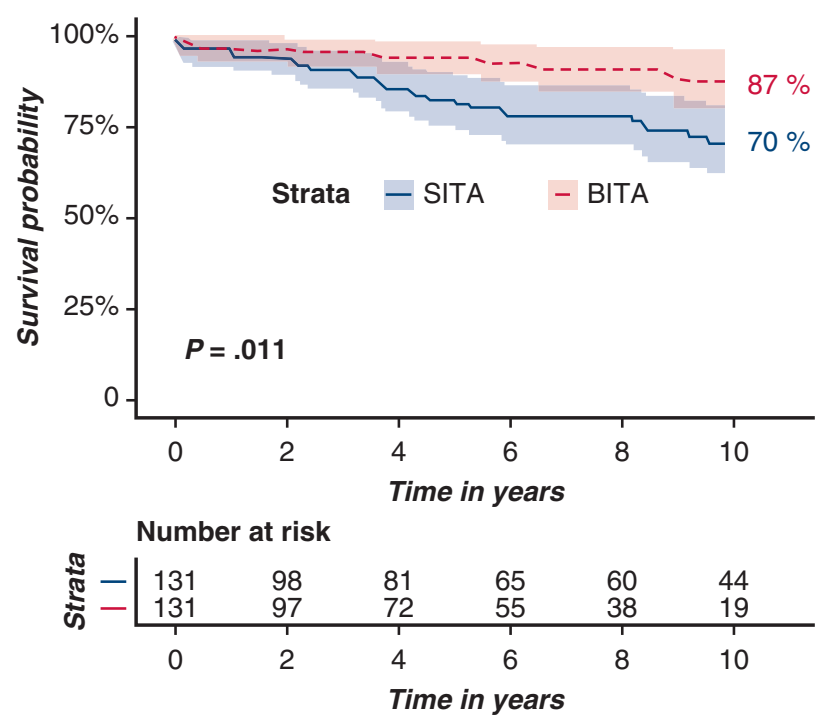

B

FIGURE 2. Kaplan-Meier survival estimates with number of subjects at risk and $95 \%$ Hall-Wellner Bands. A, SITA versus BITA female patients, entire population. B, SITA versus BITA female patients, matched population. SITA, Single internal thoracic artery; BITA, bilateral internal thoracic artery. 

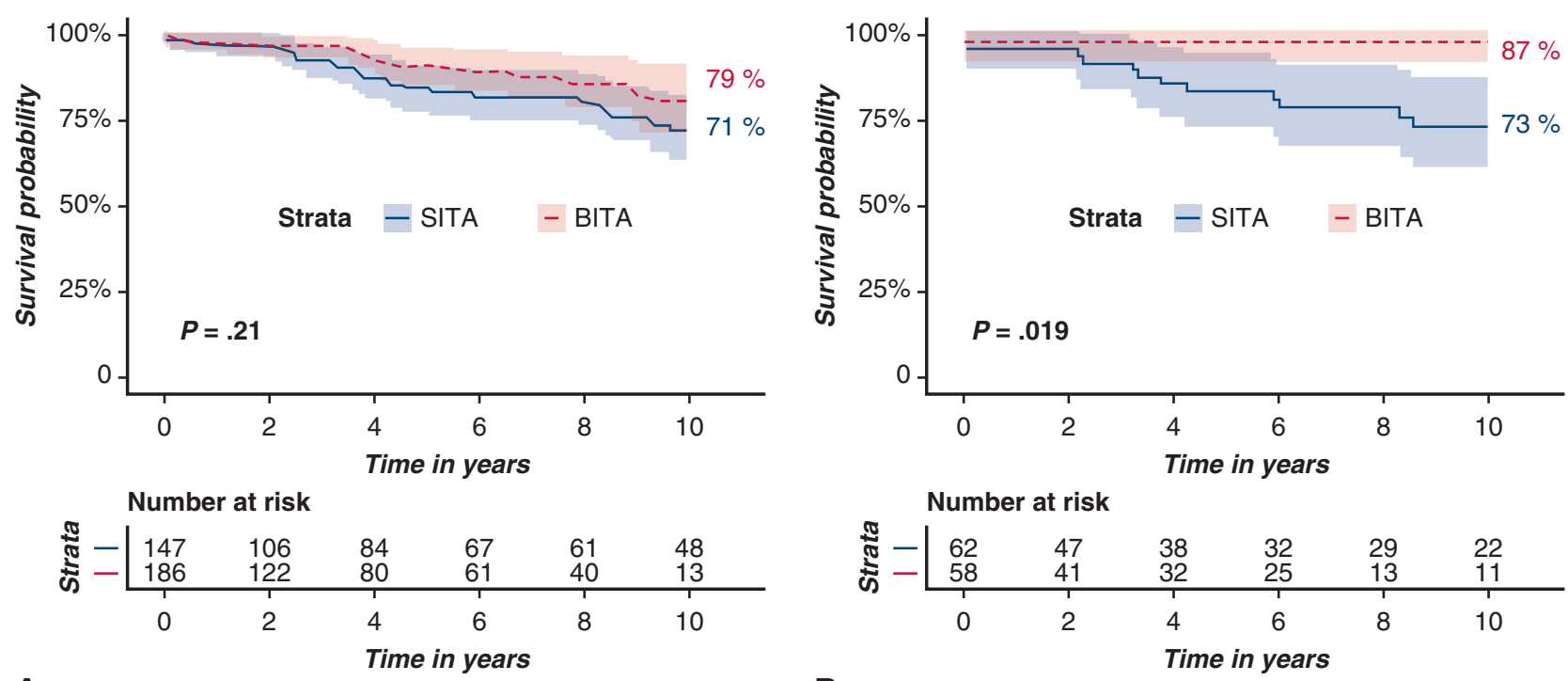

A

\section{B}

FIGURE 3. Kaplan-Meier survival estimates with number of subjects at risk and $95 \%$ Hall-Wellner Bands. A, SITA versus BITA female patients older than 65 years, entire population. B, SITA versus BITA female patients older than 65 years, matched population. SITA, Single internal thoracic artery; BITA, bilateral internal thoracic artery.

compared with old SITA patients. Kinoshita and colleagues showed better results in regarding the need for reintervention in the BITA group, similar to what Lytle reported in $2004 .{ }^{35}$ We showed that women older than 65 years with BITA have a greater long-term survival than the SITA group in the unadjusted and adjusted populations $(P=.04 \mathrm{vs}$ $P=.01$, respectively).

\section{Limitation}

The main limitations of this study include its retrospective design and single-center site. The statistical power

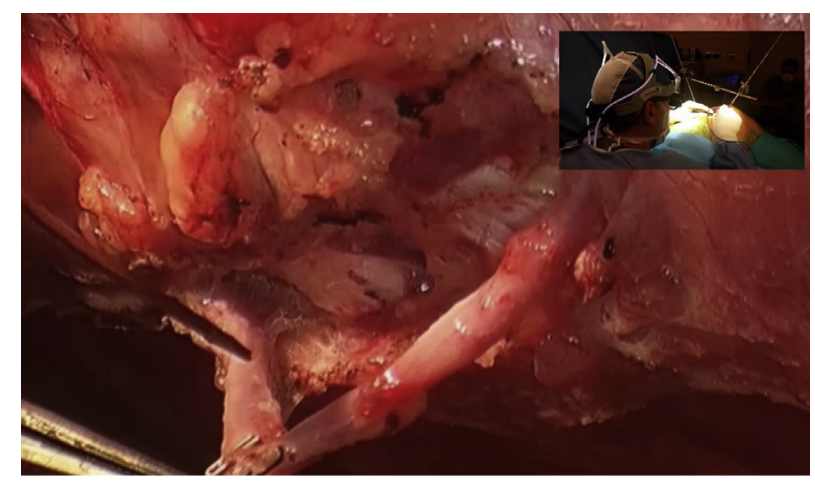

VIDEO 1. Off-pump CABG using skeletonized bilateral internal thoracic arteries in a triple vessel coronary disease patient. Opening the pericardium toward the inferior vena cava allows right ventricle positioning into right pleural space, and hemodynamic improvement during heart mobilization. After end-to-side connection of the free RITA graft to in-situ LITA, LITA is anastomosed to the LAD and RITA, sequentially, to the circumflex and distal right coronary arteries. Video available at: https://www.jtcvs.org/ article/S0022-5223(19)30234-X/fulltext. analysis was estimated for time-to-event data considering our entire female sample size $(\mathrm{n}=333)$, BITA usage $(\mathrm{n}=299)$, an overall probability of death at follow-up of $15 \%$ at 10 years, an HR of 0.7 , and type I error rate of $5 \%$, yielding an observed statistical power of $67.12 \%$. When using significance tests to make decisions about a null hypothesis, 2 types of error can be made; rejecting the null hypothesis when it is true (type I error) and failure to reject the null hypothesis when it is, in fact, false (type II error). It is well recognized that low statistical power increases the probability of a type II error. However, because our results yielded a significant statistical difference (after adjusting for important risk factors), we believe the sample size to be adequate.

There were many significant differences between both groups that might in part contribute to the higher mortality rate in the female SITA group. These are the main reasons that a risk adjusted analysis was mandatory. Although we performed 2 separate risk-adjusted analyses, including a multivariate risk analysis and propensity score matching, with the intention to minimize this bias, we are aware that some unmeasured confounders might have also affected the results.

\section{CONCLUSIONS}

Results of this study suggest that BITA grafting in women is associated with similar survival within 10 years compared with men. We also found that among women, the BITA group had better survival than the SITA group, especially in those older than 65 years. The superior results of BITA grafts are independent of sex. 


\section{Webcast}

You can watch a Webcast of this AATS meeting presentation by going to: https://aats.blob.core.windows.net/media/ 18May01/Theater\%201\%20Booth\%20134/S84\%20-\%20 Update\%20of\%20surgical\%20Ablation/S84_5_webcast_014 $629022 . m p 4$.

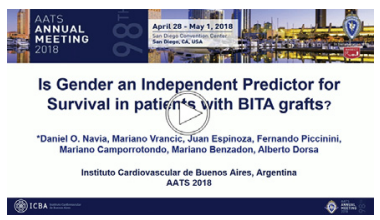

Conflict of Interest Statement

Authors have nothing to disclose with regard to commercial support.

\section{References}

1. Papakonstantinou NA, Stamou MI, Baikoussis NG, Goudevenos J, Apostolakis E. Sex differentiation with regard to coronary artery disease. J Cardiol. 2013;62:4-11.

2. Sharma K, Gulati M. Coronary artery disease in women. A 2013 update. Glob Heart. 2013;8:105-12.

3. Roger VL, Go AS, Lloyd-Jones DM, Benjamin EJ, Berry JD, Borden WB, et al Executive summary: heart disease and stroke statistics—2012 update: a report from the American Heart Association. Circulation. 2012;125:188-97.

4. Roques F, Nashef SA, Michel P, Gauducheau E, de Vincentiis C, Baudet E, et al Risk factors and outcome in European cardiac surgery: analysis of the EuroSCORE multinational database of 19030 patients. Eur J Cardiothorac Surg. 1999; 15:816-22.

5. Anderson RP. First publications from the Society of Thoracic Surgeon's national database. Ann Thorac Surg. 1994;57:6-7.

6. Vaccarino V, Abramson JL, Veledar E, Weintraub WS. Sex differences in hospital mortality after coronary artery bypass surgery: evidence for a higher mortality in younger women. Circulation. 2002:105:1176-81.

7. Jabagi H, Tran D, Hessian R, Glineur D, Rubens FD. Impact of gender on arterial revascularization strategies for coronary artery bypass grafting. Ann Thorac Surg. 2018;105:62-8.

8. Tabata M, Grab JD, Khalpey Z, Edwards FH, O'Brien SM, Cohn LH, et al Prevalence and variability of internal mammary artery graft use in contemporary multivessel coronary artery bypass graft surgery: analysis of the Society of Thoracic Surgeons national cardiac database. Circulation. 2009;120: 935-40.

9. Kurlansky PA, Traad EA, Galbut DL, Zucker M, Ebra G. Efficacy of single versus bilateral internal mammary artery grafting in women: a long-term study. Ann Thorac Surg. 2001;71:1949-58.

10. Kurlansky PA, Traad EA, Dorman MJ, Galbut DL, Zucker M, Ebra G. Bilateral internal mammary artery grafting reverses the negative influence of gender on outcomes of coronary artery bypass grafting surgery. Eur J Cardiothorac Surg. 2013;44:54-63.

11. Kramer A, Mastsa M, Paz Y, Locker C, Pevni D, Gurevitch J, et al. Bilateral skeletonized internal thoracic artery grafting in 303 patients seventy years and older. J Thorac Cardiovasc Surg. 2000;120:290-7.

12. Galbut DL, Traad EA, Dorman MJ, DeWitt PL, Larsen PB, Kurlansky PA, et al. Coronary bypass grafting in the elderly. Single versus bilateral internal mammary artery grafts. J Thorac Cardiovasc Surg. 1993;106:128-35; discussion: 135-6.

13. Navia D, Vrancic M, Vaccarino G, Piccinini F, Raich H, Florit S, et al. Total arterial off-pump coronary revascularization using bilateral internal thoracic arteries in triple-vessel disease: surgical technique and clinical outcomes. Ann Thorac Surg. 2008;86:524-30.

14. Gaudino M, Massetti M, Farina P, Hanet C, Etienne PY, Mazza A, et al. Chronic competitive flow from a patent arterial or venous graft to the circumflex system does not impair the long-term patency of internal thoracic artery to left anterior descending grafts in patients with isolated predivisional left main disease: long- term angiographic results of 2 different revascularization strategies. $J$ Thorac Cardiovasc Surg. 2014;148:1856-9.

15. Wendler O, Hennen B, Markwirth T, König J, Tscholl D, Huang Q, et al. T grafts with the right internal thoracic artery to left internal thoracic artery versus the left internal thoracic artery and radial artery: flow dynamics in the internal thoracic artery main stem. J Thorac Cardiovasc Surg. 1999;118:841-8.

16. Lazar HL, Chipkin SR, Fitzgerald CA, Bao Y, Cabral H, Apstein CS. Tight gly cemic control in diabetic coronary artery bypass graft patients improves perioperative outcomes and decreases recurrent ischemic events. Circulation. 2004 109:1497-502.

17. Lazar HL, Vander Salm T, Engelman R, Orgill D, Gordon S. Prevention and management of sternal wound infections. J Thorac Cardiovasc Surg. 2016;152 962-72.

18. Fisher LD, Kennedy JW, Davis KB, Maynard C, Fritz JK, Kaiser G, et al. Association of sex, physical size, and operative mortality after coronary artery bypass in the coronary artery surgery study (CASS). J Thorac Cardiovasc Surg. 1982;84 $334-41$.

19. Loop FD, Golding LR, MacMillan JP, Cosgrove DM, Lytle BW, Sheldon WC Coronary artery surgery in women compared with men: analysis of risks and long-term results. J Am Coll Cardiol. 1983;1:383-90.

20. Buxton BF, Hayward PA, Newcomb AE, Moten S, Seevanayagam S, Gordon I Choice of conduits for coronary artery bypass grafting: craft or science? Eur J Cardiothorac Surg. 2009;35:658-70.

21. Saxena A, Dinh D, Smith JA, Shardey G, Reid CM, Newcomb AE. Sex differences in outcomes following isolated coronary artery bypass graft surgery in Australian patients: analysis of the Australasian Society of Cardiac and Thoracic Surgeons cardiac surgery database. Eur J Cardiothorac Surg. 2012; 41:755-62.

22. Aldea GS, Gaudiani JM, Shapira OM, Jacobs AK, Weinberg J, Cupples AL, et al Effect of gender on postoperative outcomes and hospital stays after coronary artery bypass grafting. Ann Thorac Surg. 1999;67:1097-103.

23. D'Agostino R, Jacbs J, Badhwar V, Fernandez F, Paone G, Wormuth D, et al. The Society of Thoracic Surgeons Adult Cardiac Database: 2018 update on outcomes and quality. Ann Thorac Surg. 2018;105:15-23.

24. Taggart DP, Altman DG, Gray AM, Lees B, Nugara F, Yu LM, et al. Randomized trial to compare bilateral vs. single internal mammary coronary artery bypass grafting: 1-year results of the arterial revascularisation trial (ART). Eur Heart J. 2010;31:2470-81.

25. Rubens FD, Chen L, Bourke M. Assessment of the association of bilateral internal thoracic artery skeletonization and sternal wound infection after coronary artery bypass grafting. Ann Thorac Surg. 2016;101:1677-82.

26. Goh S. Post-sternotomy in the modern era. J Card Surg. 2017;32:556-66.

27. Benedetto U, Altman DG, Gerry S, Gray A, Lees B, Pawlaczyk R, et al. Pedicled and skeletonized single and bilateral internal mammary artery grafts and the incidence of sternal wound complications: insights from the arterial revascularization trial (ART). J Thorac Cardiovasc Surg. 2016;152:270-6.

28. Vrancic JM, Piccinini F, Camporrotondo M, Espinoza JC, Camou JI, Nacinovich F, et al. Bilateral internal thoracic artery grafting increases mediastinitis: myth or fact? Ann Thorac Surg. 2017;103:834-9.

29. Rieß FC, Behrendt CA, Amin W, Heller S, Hansen L, Winkel S, et al. Complete arterial revascularization using bilateral internal mammary artery in T-graft technique for multivessel coronary artery disease in on- or off-pump approach: does gender lose its historical impact on clinical outcome? Eur J Cardiothorac Surg 2017:52:917-23.

30. Hessian R, Jabagi H, Ngu JM, Rubens FD. Coronary surgery in women and the challenges we face. Can J Cardiol. 2018:34:413-21.

31. Gansera B, Gillrath G, Lieber M, Angelis I, Schmidtler F, Kemkes B. Are men treated better than women? Outcome of male vs female patients after CABG using bilateral internal thoracic arteries. Thorac Cardiovasc Surg. 2004:52:261-7.

32. He GW, Acuff TE, Ryan WH, Mack MJ. Risk factors for operative mortality in elderly patients undergoing internal mammary artery grafting. Ann Thorac Surg. 1994:57:1453-60.

33. Pettinari M, Sergeant P, Meuris B. Bilateral internal thoracic artery grafting in creases long-term survival in elderly patients. Eur J Cardiothorac Surg. 2015 47:703-9

34. Kinoshita T, Asai T, Suzuki T, Kuroyanagi S, Hosoba S, Takashima N. Off-pump bilateral skeletonized internal thoracic artery grafting in elderly patients. Ann Thorac Surg. 2012:93:531-6.

35. Lytle BW, Blackstone EH, Sabik JF, Houghtaling P, Loop FP, Cosgrove DM. The effect of bilateral internal thoracic artery grafting on survival during 20 postoperative years. Ann Thorac Surg. 2004;78:2005-14. 
Key Words: BITA CABG, BITA grafting, women CABG, off-pump surgery, women survival, women versus men

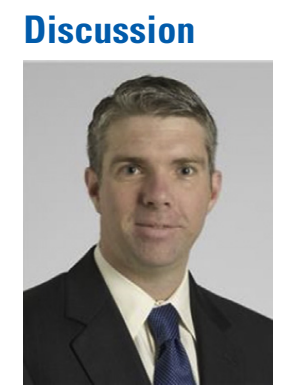

Dr Douglas R. Johnston (Cleveland, Ohio). Congratulations on this series. The outcomes are excellent and your analysis with these numbers in a single center, I mean, there are very few studies that reach this level of detail. It's interesting, when Joe Sabik reviewed our data from the Clinic, the subset analysis showed that the only group that really suffered from an increase in mediastinitis were obese, diabetic women older than the age of 65 years, and even in that group the survival benefit of BITA was there. So I was interested to see that the finding in this study was the same.

Do you have a sense of whether any changes in technique have reduced your mediastinitis rates in the latter part of the series?

Dr Daniel O. Navia (Buenos Aires, Argentina). Mainly skeletonized IMA is an issue and also to keep track of the blood sugar levels below 180 for the entire hospitalization, not just only the first 48 hours but until the patient is going home. That may contribute to that.

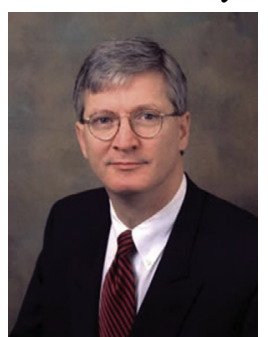

Dr John D. Puskas (New York, NY). I wanted to congratulate you on a terrific presentation. That's a beautiful series. We did a similar series at Emory when I was there years ago and discovered that double mammary grafting benefited patients in the modern era when we had over $50 \%$ diabetics just as it had in the era of Floyd Loop at the Cleveland Clinic when they had less than $15 \%$ diabetics. Nonetheless, despite the diabetes, the survival advantage of 2 mammaries versus 1 was present in a propensity-matched large series, 15,000 patients.

We also found that it narrowed the gap between men and women in longer-term survival after coronary bypass surgery, which is remarkable, because women don't do as well after coronary bypass as men, and double mammary grafting seems to benefit them a great deal. So you have demonstrated that very nicely.

Dr Navia. Thank you very much.

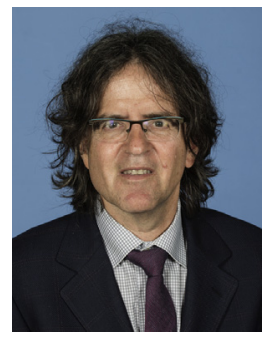

Dr Niv Ad (Falls Church, Va). The one thing that can add I think to your excellent data and information is to look into risk control over time with cholesterol and hypertension and diabetes control over time with A1c. I know it's very hard with a retrospective study, but maybe in a subgroup of these patients you may have good data, because it's a large group of patients and it can further improve the outcome over time, especially in this group of patients.

Dr Navia. You know, this was 17 years' retrospective study presentation. In the past 5 years these results are much better and I think it would be easy to analyze the issues of risk control. I will take this idea back home for further analysis.

Dr Johnston. What are your thoughts on the recent randomized trial findings of no difference between BITA and SITA survival in light of your single institution experience?

Dr Navia. You have to wait 10 years.

Dr Johnston. I think the same thing. 
TABLE E1. Patient characteristics and intraoperative data (all patients) sex comparison

\begin{tabular}{|c|c|c|c|c|}
\hline Preoperative variable & Male sex $(n=3858 ; 87.6 \%)$ & Female sex $(n=548 ; 12.44 \%)$ & $P$ value & SMD \\
\hline Median age [IQR] & $64[58-71]$ & $69[63-75]$ & $<.001$ & 0.47 \\
\hline Median weight [IQR] & 83 [75-92] & $68[61-78]$ & $<.001$ & 0.509 \\
\hline Median height [IQR] & $172[169-178]$ & $160[155-163]$ & $<.001$ & 2.02 \\
\hline Hypertension, $\mathrm{n}(\%)$ & $2929(75.9)$ & $436(79.6)$ & .068 & 0.088 \\
\hline Smoking history, n (\%) & $2439(63.2)$ & $218(39.8)$ & $<.001$ & 0.482 \\
\hline Diabetes mellitus, n (\%) & $1061(27.5)$ & $170(31.0)$ & .095 & 0.077 \\
\hline Family history of coronary disease, $\mathrm{n}(\%)$ & $828(21.5)$ & $132(24.1)$ & .181 & 0.063 \\
\hline Previous MI, n (\%) & $1631(42.3)$ & $193(35.2)$ & .002 & 0.145 \\
\hline Previous PCI, n (\%) & $831(21.5)$ & $92(16.8)$ & .012 & 0.121 \\
\hline Redo surgery, n (\%) & $102(2.6)$ & $11(2.0)$ & .461 & 0.042 \\
\hline Peripheral artery disease, $\mathrm{n}(\%)$ & $130(3.4)$ & $21(3.8)$ & .666 & 0.025 \\
\hline COPD, n $(\%)$ & $225(5.8)$ & $15(2.7)$ & .004 & 0.153 \\
\hline Cerebrovascular disease, $\mathrm{n}(\%)$ & $143(3.7)$ & $19(3.5)$ & .875 & 0.013 \\
\hline Renal dysfunction, n (\%) & $199(5.2)$ & $25(4.6)$ & .624 & 0.028 \\
\hline Anemia, n (\%) & $182(4.7)$ & $71(13.0)$ & $<.001$ & 0.293 \\
\hline Impaired ejection fraction $(<0.40), \mathrm{n}(\%)$ & $637(16.5)$ & $71(13.0)$ & .04 & 0.1 \\
\hline Left main CAD, n (\%) & $887(23)$ & $105(19.1)$ & .177 & 0.12 \\
\hline Median vessel disease [IQR] & $3[3-4]$ & $3[2-3]$ & $<.001$ & 0.352 \\
\hline Nonelective surgery, n (\%) & $1346(34.9)$ & $259(47.3)$ & $<.001$ & 0.254 \\
\hline \multicolumn{5}{|l|}{ Intraoperative data } \\
\hline BITA - SITA, n (\%) & & & $<.001$ & 0.317 \\
\hline SITA, n $(\%)$ & $1023(26.5)$ & $207(37.8)$ & & \\
\hline BITA, n (\%) & $2680(69.5)$ & $299(54.6)$ & & \\
\hline Other, n (\%) & $155(4.0)$ & $42(7.7)$ & & \\
\hline On-pump, n (\%) & 487 (12.6) & $87(15.9)$ & .04 & 0.093 \\
\hline Median number of grafts [IQR] & $3[3-4]$ & $3[2-3]$ & $<.001$ & 0.352 \\
\hline Median bypass time [IQR] & $100[85-117]$ & 89 [73-101] & $<.001$ & 0.479 \\
\hline
\end{tabular}

$\overline{S M D}$, Standardized mean difference; $I Q R$, interquartile range; $M I$, myocardial infarction; $P C I$, percutaneous coronary intervention; $C O P D$, chronic obstructive pulmonary disease; $C A D$, coronary artery disease; BITA, Bilateral internal thoracic artery; SITA, single internal thoracic artery. 